\title{
The joy of teaching and learning in academia - teachers' perspectives from three countries
}

\author{
Alina Georgeta Mag ${ }^{1,1,}$ Sandra Sinfield, Tom Burns ${ }^{2}$, and Sandra Abegglen ${ }^{3}$ \\ ${ }^{1}$ University "Lucian Blaga" of Sibiu, Faculty of Social and Human Sciences, Department for Teacher Training, Calea \\ Dumbrăvii Nr 34, 550324, Sibiu, România \\ ${ }^{2}$ London Metropolitan University, London, N7 6PP, United Kingdom \\ ${ }^{3}$ University of Calgary, 2500 University Drive NW Calgary, Alberta, Canada
}

\begin{abstract}
All over the world, the educational landscape has changed dramatically over the last year, impacting the way we teach and learn. It is time for reflecting and searching for new ways to support each other, during these pandemic times and beyond; time to co-construct creative partnerships and to innovate new ways to co-create. Change is an inevitable part of teaching and learning but the adaptations currently required are of unprecedented scale. How can we teach and learn with joy in today's academia? How can we support each other, as teachers, in more creative ways? These two reflective questions were at the base of the study, which was conducted by university teachers from three countries: "Lucian Blaga" University of Sibiu, Romania; London Metropolitan University, United Kingdom; and University of Calgary, Canada. The methods used included interviews, focus groups and free writing with colleagues in each university. Findings revealed the challenges faced by each participant due to the emotional pressure caused in these supercomplex times, and the struggle to bring joy of teaching and learning in creative ways. This small ethnographic project reveals a need to shift our thinking about emotions and how we may facilitate the greatest success of all our students, by continually inventing new solutions and teaching with enthusiasm.
\end{abstract}

\section{Introduction}

The global crisis provoked by the Covid-19 pandemic, has impacted the academic environment rapidly, all over the world. The way we teach and learn is challenged more than ever. University teachers are looking for new solutions to keep students active and motivated to learn, during pandemic times and beyond. Change has always been an inevitable part of teaching and learning, but how do we really feel about what is happening today? How can we teach with joy when the world we live in is very demanding? Colleagues from three different countries, Romania, United Kingdom and Canada, came together looking for a piece of hope in these challenging times, to co-construct creative partnerships and to innovate new ways to perform.

We argue that it is time to reclaim joy in learning and teaching - and in our lives in general - because teaching can be tough and overwhelming without colleagues' support and understanding. Caring teachers endeavour to enrich academic education and students' lives, even as they embrace the virtual, adopting new ways of teaching and learning. Studies argue that teachers affected by stress and burnout can hardly focus on their well-being, and teachers' state of well-being is linked with students' education, with university's ability to meet diverse needs and with teachers' sense of purpose and success [1-2]. "Joy in teaching provides the tools and resources to turn things around for educators, to make teaching a desirable and joy-filled experience", that impacts students as well, through all their efforts of learning [1].

\footnotetext{
${ }^{1}$ Corresponding author: $\underline{\text { alina.mag@ulbsibiu.ro }}$
} 


\section{Problem statement}

Today's academic reality requires a much greater focus on well-being, with the joy of teaching and learning being often neglected in praxis. It has been recognized, by research and practitioners, that joy plays a decisive role to create a meaningful life in education [1]. The feelings experienced by teachers, so personally, impact on students' motivation to learn and make a huge difference in their lives.

First, it is important to clarify the meaning of the notion of 'joy', which is described as a feeling of great pleasure and happiness [2]. In these lean, mean, and pandemic times, joy is what is not in the foreground of our lives and our minds. Yet, joy is essential. It is what makes us 'tick', what motivates us, what brings that little bit of extra sparkle into our lives. Joy can mean many things: being with others, sharing (experiences, laughter, tears - and food) - a generally vibrant feeling of happiness. The philosophy of happiness (which is not the same as joy, but close) can improve teachers' efforts if they come together to support each other and to co-construct academic education through creative collaborative practices that foster joy and well-being. Aristotle was convinced that a genuinely happy life requires the fulfilment of a broad range of conditions, including physical as well as mental well-being. In this way he introduced the idea of a science of happiness, as a new field of knowledge and study [3].

This ethnographic project is simply getting clear on what a small group of university teachers from three different countries speak and write about their own joy of being teachers in academia. In this context, 'joy' is used as a value term, roughly synonymous with well-being or flourishing, with each participant corresponding to a personal sense of the word [2]. Thus, the present article focuses on joy in the psychological sense, through personal views and perspectives, in the hope to inspire others, and to change current approaches to teaching and learning.

\section{Theoretical foundation}

Theories of well-being and hence of 'happiness' or 'joy' in the well-being sense come in three basic flavors, according to a well-known taxonomy [4]: hedonism, desire theories, and objective list theories. Hedonism identifies well-being roughly with experiences of pleasure, while desire theories equate it with the satisfaction of one's desire. Both theories are in some way subjectivist since they ground well-being in the individual's subjective states or personal emotional-affective experience. Objective list theories, by contrast, argue that some things benefit us independently of our attitudes or feelings: there are objective prudential goods that benefit us whether we desire them or not. Aristotelians are the best-known example, they take well-being (Greek: eudaimonia) to be the fulfillment of our human capacities throughout life - a virtuous activity [4].

However, to reveal the needs of joy in education, we need to dig deeper and explore what life satisfaction means, according to recent studies [1-3]. Life satisfaction theories identify happiness or joy with having a positive attitude toward one's life - and life in general. This basic schema can be interpreted in a variety of ways, but typically involves some sort of global judgment (or accompanies some aggregate of judgments) about items or domains within one's life [4].

Thus, happiness could be considered a major component of a theory of well-being. Objective list theories of well-being sometimes include happiness or related mental states such as enjoyment among the fundamental constituents of well-being but also other theories acknowledge happiness as an important part of our life. However, others forsake the idea of a unitary theory of well-being, recognizing instead two or more kinds of prudential value. Happiness could be central to, or even exhaustive of, one of those values. Shelly Kagan, Clark Professor of Philosophy at Yale University, for instance, has suggested that welfare hedonism could be seen as a theory of how well a person is doing, but not of how well a person's life is going [4].

In this context, an interesting possibility is that the locution 'happy life', and the corresponding well-being sense of happiness, refers to a specific variety of well-being: well-being taken as an ideal state, a goal of deliberation. This might explain the continued use of 'happiness' for the well-being notion in the philosophical literature, rather than the more standard well-being' [3-4].

Beyond that, a consideration of joy 'needs' and 'desires' are important for the teaching profession and form the focus of this study. Bell hooks' "Theory as Liberatory Practice", the fifth chapter in Teaching to Transgress, aims to theorize learning as a freedom enhancing experience through the tools of accessibility and pleasure. One of the top questions is: How to find joy in teaching - as a professional? Because teaching is a stressful job, even in non-pandemic times, simple steps can help build happiness in the profession. For example, slowing down and reflecting can help not only to restore joy, but also to benefit classroom culture [5].

Further, it is important to look beyond the teacher at the education environment in which they and the students are situated. Self-efficacy is something that concerns those that teach as well as those that are taught. Developing a student's self and intrinsic motivation starts with establishing the belief that everyone matters. Thus, deliberately investing time in each student yields big dividends. Writing positive, encouraging, specific feedback on their papers, using their names and acknowledging their effort are ways to foster trust and joy. This 
type of personalized attention shows students that the teacher cares about their individual well-being. Also, despite workloads and time pressures, colleagues are some of the best resources. Seeking out the guidance of others, a school counselor, other teachers, colleagues from other institutions, is a great practice. Peers with different perspectives can be important assets in regaining joy. Colleagues can also remind each other why they became teachers in the first place [5].

A related body of studies explores the costs and benefits of joy in education - for educators and learners [36]. Teachers are the ones that witness the diversity of growth in young people, and their joy (or struggle) in learning that encourages (or hinders) lifelong learning. They also experience the challenge of creating and delivering interesting, exciting activities for their learners. There is obviously much more to be said about the value of teaching and the challenges and joys of being an educator. "A teacher's job - in fact, a teacher's privilege - is to help particular young people to realize their potential" [6].

The knowledge may be about science, math, or learning to read; the skills may be sports, music, or art, anything. Whatever the subject and skills, if handled creatively, education can be a source of curiosity, wonder and excitement. It can be a reason to be optimistic about life in general. Learning is never-ending, even though it often focuses on short-term, immediate concerns like the passing of tests and good grades.

Teachers have an advantage, not shared by other professions, namely the excuse not only to teach valuable knowledge and skills, but to point students beyond what they will be able to learn from them, to further opportunities [5-6]. This privilege should be at the base of the joy teachers are living. Whatever they teach, teachers will be able to feel the satisfaction of designing and orchestrating complex activities that develop new ideas and skills, aptitudes, and practices. The challenge is attractive to many teachers because that is where they exercise judgment and 'artistry' the most freely and frequently. The job never stays the same, it evolves continually. If teachers keep teaching, they will have a job with novelty [6].

"Nothing is more important than having enthusiasm, if you are a teacher" according to Ron Clark [7]. Students will be excited to learn if teachers are eager and excited to teach. Thus, teachers need to be aware of their own attitudes and emotions so they can inspire students and motivate them to learn, to have a desire to achieve, and to want to be the best person they can be. Also, when teachers are active and truly enthusiastic about their jobs, they are much happier [7], and their students may be also.

In today's supercomplex world where high achievement matters, and is measured by one's value in the marketplace, many students are asking questions about progress and prestige after they graduate, without understanding that the journey of life should be about happiness and joy, also. The level of depression is increasing worldwide because the sense of self fulfilment is not identified [8]. We are centering most of our energy on material, scientific or technical domains, rather than our emotional and psychological ones. Adults should admit the vital necessity of emotional education during life, because the efficiency of school in all areas, without emotional balance and fulfilment, is not enough [9]. There is something else needed for authentic learning to happen and young people to find a purpose in life.

This project is based on these theoretical groundings that reveal the importance of joy in education. Each of these closely relate to the ethics of joy that contributes to the discussion about the best way of teaching and learning in today's academia. The ethics is not about what a person deserves, or what makes a person praiseworthy or blameworthy, but it is about how to live and work joyously and lovingly, not sadly and hatefully [10]. Education is a live system which exists through all multiple daily ways of human actions and interactions. The system can be changed if teachers and colleagues, together with students, co-create and coconstruct education, building creative partnerships and fostering well-being in each institution and each other. The new technologies, if embraced creatively, can facilitate these new dynamic partnerships between teachers, students, and experts in all areas [11] - and beyond geographical boundaries.

\section{Purpose}

The Covid pandemic forced schools and universities to close and switch to remote delivery. This also meant adopting digital technologies 'at a stroke', immediately, with little or no preparation or exploration of how to use them to promote holistic, humane teaching and learning. The increasing availability and sophistication of digital software and tools transformed the world in which teachers teach, students learn, and how they teach and learn. While, on the one hand, we are connected to each other 24/7, we are, on the other, further apart from each other, hidden behind screens with limited possibility to meet and interact. For example, chance encounters have nearly disappeared and so has the spontaneous banter and laughter. This small project's purpose was to explore practitioners' perspectives on two sensitive topics, to clarify their understanding of joy in academia and actual needs of colleagues' support:

- How can we teach and learn with joy in today's academia?

- How can we support each other, as teachers, in more creative ways? 
These two reflective questions were at the base of the study, which was conducted by university teachers from three countries: Romania - "Lucian Blaga" University of Sibiu, United Kingdom - London Metropolitan University, and Canada - University of Calgary. We analyzed the responses of all participants and compared the answers to search for new ways of developing collaborative support and creative partnerships between teachers during these difficult times.

\section{Methods}

The methods used included interviews, focus groups and free writing with colleagues in each university. The number of respondents, eight university teachers voluntarily involved, was represented by five from "Lucian Blaga" University of Sibiu, Romania, two from London Metropolitan University, and one from University of Calgary, Canada. The UK/Canada academics all had 10 year or more experience in higher education so were experienced teachers. They were experts in education, social sciences, and design. Two of the participants were female and one was male. The Romanian academics involved all had 10 year or more experience in higher education too, except for one teacher, who was a young assistant at the beginning of his academic career. Two of the participants were male and three were female. They were specialized in different fields: education, journalism, and public relations.

We have adopted an ethnographic approach, sharing our reflective questions with practitioners. In this way we attempted to collect multivocal, heteroglossic feedback/thoughts/data, allowing us to produce, draw together and interpret our several personal stories. Thus, we embrace the collaborative and the self: "using the self as evidence to empower others rather than using others as evidence to empower the self" [12]. Ethnography is located within the broader enterprise of qualitative inquiry, and "as method, seeks to disrupt the binary of science and art" [12]. Our inquiry erases no voices, our collaborative process allows us each to speak - to have a voice. The process is reflective and reflexive - a process that is "slippery, a house of mirrors, as the self and its discursive construction cannot be pinned down definitively" [12]. Our researchers' selves are "the ethical axis where reflexive ethical deliberations must take place" [12]. We do not claim objectivity, we acknowledge that these 'accounts' are partial and situated in this place and time. Yet, they are incredibly powerful in that we are all interconnected, and thus they provide insight into current experiences and emerging discourses. The methods used allowed us to capture the voices of practice, in a period in which pandemic burnout is rampant in academia [13-14].

\section{Findings}

Responses show that quality relationships have a huge impact on each participant's personal motivation and state of well-being, as teachers. Participants were selected based on their interest for the topic studied and their profession. Teachers' perspectives related to joy and creative collaborations painted a complex and significant picture. Findings also underscore that teachers' reflections were emotional, variable and context dependent. The ethnographic approach was useful to share our reflective questions with practitioners voluntarily from each country. An important reason to involve a small number of respondents to provide their reflections was directly related with the sensitive topic of our project, designed with the purpose to collect sincere and deep personal reflections. Another reason was to provide practitioners the chance to call for university teachers' awareness for the power of joy in today's academia, and for creative ways in which teachers can support each other, during the pandemic. If teachers find the way to succeed, in difficult times, students will do the same. Ethics approval was sought and given, according to each university ethics policy and the interpretation of each participant's personal reflections were anonymized and revealed with their consent.

University teachers were invited to take part in interviews and focus groups meetings based on their options to become voluntary co-researchers, in each institution involved in this project, from three countries: "Lucian Blaga" University of Sibiu, Romania, London Metropolitan University, United Kingdom, and University of Calgary, Canada. The reflective questions were at the base of the study and after the meetings, participants used free writing to express their personal views and reflections. The topic discussed was of great interest for all participants, which was essential for the small ethnographic investigation.

In each institution, the focus group meetings started with a needs' analysis of the significant emotions and needs of support from colleagues, especially during the current crisis, mixed with the huge challenge to transform education into a virtual one so fast. The level of stress and the lack of psychical socialization were discussed and questioned, to gain a deeper understanding of participants' perception. The pandemic changed so much the teaching profession in a critical time both for students and teachers. The interviewer of each institution asked a series of open-ended questions related to their own experiences, about their feelings during teaching through the digital tools and the kind of support they prefer and about the relevance of joy for teaching and 
learning during a world medical crisis. Focus groups were followed by free writing of reflections which were recorded as the participants' answers.

The data collected from all the respondents were used as relevant information, because every respondent has a significant background in terms of professional experience. We believe that the opinions expressed 'give a sense of' the range of voices of the university teachers in their academic communities, in each country. Their voice is powerful and meaningful. The voices collected - collaborative and individual - allowed us to uncover needs and opportunities for further reflections about such delicate subjects, to empower others to express their voice. A qualitative approach was used to collect data that provided details like feelings, emotions, and reflective and reflexive thoughts. Deep reflections were revealed to generate new ways of understanding the joy of teaching and learning, in communities of teachers that co-construct the support needed.

At the first question - How can we teach and learn with joy in today's academia? - the data registered allowed us to gain insights into teachers' understanding and practice of their complex role. Responses revealed individual differences and perspectives to explain what joy really means in this role, as teachers, during today's crisis. All participants responded that joy is important to them and it is indispensable for their teaching and learning, also for constant improvement. Teachers emphasized joy's role as a strong motivator to be a better teacher. They recognized the power of joy to support their daily teaching and learning efforts. Here are samples of participants' answers, in the three countries.

- Romanian respondents:

- "My teaching involvement includes: general mindsets, like: I care about the people in front of me, that is why I focus primarily on them, not me; students learn from me, but I also learn from them all the time; mutual curiosity keeps us connected; I teach because I love to share not only knowledge, but also values or emotions; if I feel good about my students, they will feel these vibes and they will be open to learning new things; playing is always an excellent means of learning, regardless of age; so we often play seriously and laugh; specific methods (Covid-19 context) like: I don't force them to turn on their camcorder, but I show them how happy I am to see their faces when they do that; I pay attention to feedback, especially nonverbal ones; I ask for verbal feedbacks especially from more shy or introverted students; I listen to every opinion, with respect and the wish to understand, even when they are radical; I use examples, visual metaphors, provocative questions, quizzes, infographics; I often learn to use digital apps or tools to be closer to their expectations; emotions, emotions, emotions, for memorable connections with my students; I use all communication channels with students (social media groups, telephone), for informal communication and email, also classroom platform for formal communication."

- "Ways to create and maintain an optimistic attitude in teaching: creating an atmosphere, a pleasant educational climate, based on mutual respect and trust, the interweaving of specialized themes with topical themes, anchored in the reality of the present, use of resources, teaching strategies adapted to the online activity, identifying, and capitalizing on the positive aspects, the strengths of online teaching."

- " "As for me, the pandemic did not affect my teaching behaviour. I continued to teach with enthusiasm and the same empathetic attitude towards students. I kept the joy of reunions, even though we had to teach online. Teaching involves continuous learning. As a compensation, during this period we had almost constant access to the specialized literature, because our university facilitated our access to international databases. Those who have the joy of teaching and the constant enthusiasm for learning are never overwhelmed by temporary crises."

- "For me personally, the motivation to teach did not decrease or increase during the pandemic. I like what I do, and I feel that every moment was a challenge. In the long run, I do not like teaching in the online environment, but if it is temporary and imposed by objective circumstances, I accept it. The motivation to teach came from: 1 / the fact that I see this period as temporary and 2 / the general maintenance of a positive attitude towards life."

- "First, I think we should keep in our mind the idea of teaching our students exactly the way we would have loved to be taught when we were students. And to remember our models and mentors - amazing people who built in us not only strong knowledge but also healthy attitudes towards the others. It is also very important to know that we must create relationships and attachments with our students first and after that comes the knowledge. When the relationship is there, the joy, the curiosity, the motivation, and this great capacity of wonder will be also there! I also want to say that I am a big fan of Service Learning, this kind of learning that is connected to the community needs. Neuroeducation is telling us today that learning should not be just cognitive but also emotional and practical. In the end, I want to add that giving to our students the feeling of "being seen" and "being heard" creates trust, motivation, and involvement in this process, both for them and for us."

- United Kingdom and Canadian respondents worked in the same focus group: 
- $\quad$ "Being with others - sharing experiences, laughter, tears - and food - all these are joyful and create joy. This is necessary for survival and for innovation."

- "Share - show the joy we have, because teaching is a privilege and an urgent one at that."

- "I still feel joy when teaching; also 'marking' with joy ... there is such fantastic talent out there - but it needs help to free it, develop it and nourish it. That is a joy of being a teacher".

- "Offering random acts of food can help with joy. I have tea and biscuits in my office - but more than that, I love to surprise my students with random acts of food."

- "Smile, laugh, and be a mirror: show others how clever they are."

- "Allow students to 'BE' and become the person and professional they dream of."

- 'Always be 'fallible' - engaging in authentic knowledge construction, revealing knowledge claims and the challenging of them. This creates joy because using social constructivist methods of teaching and learning makes space for the students - it lets them in."

- "Find your friends and allies and hold on like grim death!"

- "Find the people who will sustain you - who you can discuss your teaching with - who you can write with..."

- "Meet for tea - go for lunch (even virtually)."

- I read a book (on positive thinking) that said, 'Do not wait for others to reach out and make friends, be brave, reach out, you have nothing to lose'. I took that advice in my teaching; I have made many good friends and I have not looked back."

- "Look around and find something, anything no matter how small, that you can do together with your friends or allies in your University."

- "Look for 'somewhere' to write about what you are doing together. Write together. The writing becomes a space of joy."

- "Look at loads of random educational journals - and find a Call for Papers - and think, 'We could do that!' then do it together."

- "Once you have your friends and allies, take pleasure in each other. Make each other smile. See the joy in what else they are doing. Be focused and driven - but also, do not be, make the time to just relax together."

- "Take the time to chat and follow through on thoughts and meanderings."

- " "Also, in difficult times keep your friends close, closer - be and feel closer to those friends and allies."

The second question - How can we support each other, as teachers, in more creative ways? - allowed teachers to speak and write about their own perspectives and needs of getting support from colleagues. Participants provided signals that their individual goals could meet their needs only through a continuing dialogue inside each group/department. They also recognized that everyone is different, so the inquiry of listening to each other's voice was valued as crucial. On the other hand, their individual needs are constantly changing, they are not static. Creativity is the key to find new ways to offer constant support to colleagues. All respondents claimed that the most important need for a group to function well is the quality in their interactions, so emotional intelligence needs more attention than ever. There is no place for creativity without qualitative interactions. These types of teachers create a positive and comfortable support, based on respectful and trustful relationships that are helping them feel positive, secure, and valued as a colleague. Here are examples of direct answers from respondents involved in each country.

- Romanian respondents:

- "I think it is important to develop a culture of mutual collegial appreciation, first. If a member of the academic community is successful, this is an excellent step for the whole community. We are in the same boat, and our common goal is to paddle in the same direction. When one of us has more strength, we must applaud, when one of us gets tired we must support him. And we all have harder times, we cannot work non-stop at full capacity. This is how I understand our solidarity. So: to be attentive to the needs of others, to be altruistic with resources that we believe would be useful to our colleagues; to collaborate real, with interest; to share teaching experiences. Such as, for example, having a meeting about the funniest or most embarrassing moments we have experienced teaching online. The year 2020 was one in which we had to be both resilient and creative. I think we have a lot to share."

- "Ways to create and maintain an optimistic attitude in relationships with colleagues: developing relationships based on respect and trust in colleagues, altruistic attitude by providing continuous support to colleagues, providing opportunities for personal and professional development, participation in joint activities on specialized topics but also in extracurricular activities, good management of difficult situations, dominated by tensions and conflicts by trying to find solutions, to capitalize on the potential of each colleague and not by emphasizing its limits."

- "In the last year, we have accepted many invitations to participate in pedagogical training courses to face all the challenges. In addition, we frequently had online meetings with colleagues to look for solutions to optimize the design and implementation of educational content, as well as evaluation." 
- "Creativity workshops, on various topics, both online and offline; exchange of experiences, discussions."

- "We can always start by simply talking, by sharing our experiences, especially the "not so good" ones. The challenging moments in our work and what we have learned from them. Creativity means connecting the dots and we should keep in mind that we can do this better in a collective way rather than individually. So, talking about this mutual support, I think that cooperation not competition is the best word to describe it."

- United Kingdom and Canadian respondents:

- "Find ways to work together."

- " "Find creative things to do in each other's classes."

- "Do not be shy - it is time for the academic 'viking': be bold and embrace and enjoy life - celebrate others. - take a risk."

- "Show to others how clever and joyous your colleagues are."

- "Move beyond your close colleagues in academia and embrace other stakeholders (the librarians, the Counsellors, the student support services): look for those that may be in need. People need friends they need to be celebrated. They need others to see their achievements, their joy, and dreams."

- "Do something creative - then write about it with your friends and colleagues."

- "Join the \#creativeHE Community:

- https://creativehecommunity.wordpress.com/2021/03/03/quick-and-dirty reflective-blog-about-ourlast-creativehe-meetup-on-building-communities/, and get involved."

- $\quad$ "Get involved with Creative Academic:

- $\quad$ https://www.creativeacademic.uk/creativity-in-practice.html.”

- "Join other academic communities and networks, for example TALON, the Teaching and Learning Online Network: https://taloncloud.ca."

- "Enroll on short creative courses - perhaps via \#creativeHE - and ask to write or work with people if you see they are interested in the same things as you."

- "Do an art-based Massive Open Online Course (MOOC) - and let the activities there influence your teaching practice."

- "See MoMA or Coursera to see what free open online courses they are running that are art-related and sign up!"

- "After each creative session that you do - think: how can I use that in my pedagogy and practice?"

- "Start a creative course and blog about it - then see where the connections lead you. (e.g. I started my first MOOC January 2013: Edinburgh University's E-learning and Digital Cultures [\#edcmooc]. I started to blog about it on an old unread blog (http://lastrefugelmu.blogspot.com/2013/01/) that I had used before and that no one, seriously no one read. After being on that MOOC, my blog readership went from about one person - to 2000 hits. From there I was invited to be a Course Tutor on a subsequent run of \#edcmooc - and people from the \#creativeHE community asked me to co-facilitate some online courses."

- " "Reaching out and doing something, anything, one small creative thing, can lead to so many possible rhizomatic outcomes. Then make space to think how to really foster it and make it part of what you do in creative ways."

The ethnographic approach allowed us to find common needs and creative perspectives from teachers of all three countries. Findings revealed the challenges faced by each participant due to the emotional pressure caused by recent times and the struggle to still bring joy of teaching and learning in creative ways. A comparative analysis of all the answers proves that we can learn amazing new ideas from each other, and that creativity is the best solution to cross critical challenging times in academia. In line with the findings, teachers involved recognized the value of joy as central to improve teaching and learning. Colleagues need to engage more with colleagues and find more opportunities to co-construct supportive partnerships in creative ways.

\section{Conclusions}

The Covid pandemic has changed education all over the world. One of the top priorities for teachers and students was adapting to teaching and learning online, as in-person classes were suspended. The new virtual reality of academia impacted each of us in a different way. Learning new experiences can be challenging and sometimes stressful. Students and teachers learned fast to use the digital technologies to continue education: at the same time a mirror was held up not just to our teaching now, but to our pre-pandemic practice. So often, the emotional aspect of teaching and learning gets forgotten. One positive element of this study was to raise awareness to the human basic needs to feel valued and recognized, as a specialist in academic education, as a colleague, as a human being. Joy is essential to feel well about the teaching experience and colleagues' support 
is vital, because the only way we can join others in a group, needs to be based on emotional security, solidarity, and the feeling that you belong, that you are accepted and valued.

The process of speaking out and free writing about the joy of teaching and learning and finding the joy in collaborating in new and creative ways, allowed us to gain a deeper understanding of the challenges of being a teacher now. This small ethnographic project brings a need to shift our thinking about what role emotions play in education and in particular in teaching as well as the importance of well-being in the classroom. We therefore need to further explore how we may facilitate the greatest success of all our students by not only continually inventing new solutions but also by caring for each other. Joy appears to be important for this, as an essential emotion that drives both teachers and students' success. The impact of the study is relevant both for the teachers involved and their academic communities, to improve their relationships, to be resilient and more powerful together.

\section{References}

1. https://joyinteaching.com, [Accessed 17.03.2021]

2. https://www.merriam-webster.com/dictionary/joy, [Accessed 18.03.2021]

3. https://www.pursuit-of-happiness.org/history-of-happiness/aristotle/, [Accessed 16.03.2021]

4. https://plato.stanford.edu/entries/happiness/, [Accessed 17.03.2021]

5. https://www.edutopia.org/article/ways-reclaim-your-joy-teaching, [Accessed 17.03.2021]

6. https://courses.lumenlearning.com/educationalpsychology/chapter/the-joys-of-teaching/,[Accessed 18.03.2021]

7. R. Clark, The excellent 11: quality teachers and parents use to motivate, inspire, and educate children, (Hyperion, New York, 2004)

8. T. Ben-Shahar, Happier: learn the secrets to daily joy and lasting fulfillment, (Curtea Veche Publishing, București, 2009)

9. A. de Botton, The school of life - O Educație emoțională, (Editura Vellant, București, 2020)

10. A. Youpa, The ethics of joy: Spinoza on the empowered life, (Oxford University Press, 2020)

11. K. Robinson, Creative schools: the grassroots revolution that's transforming education, (Publica, București, 2015)

12. J.C. Lapadat, J.C, Ethics in autoethnography and collaborative autoethnography, Qualitative Inquiry, 23(8), pp. 589-603 (2017).

13. https://www.nature.com/articles/d41586-021-00663-2, [Accessed 16.03.2021]

14. https://hybridpedagogy.org/foreword-voices-of-practice/, [Accessed 16.03.2021] 